\title{
Blastocyst selection criteria: towards day five single embryo transfer
}

\section{Seleção de blastocistos: em direção à transferência única}

\author{
Javier Crosby, $\mathrm{PhD}^{1}$,Antonio MacKenna, $\mathrm{MD}^{1}$ \\ ${ }^{1}$ Unit of Reproductive Medicine Department of Obstetrics and Gynecology \\ Clinica Las Condes \\ Redlara accredited center
}

\begin{abstract}
Objective: To establish morphologic criteria for blastocyst selection to decide single embryo transfer Methods: Retrospective analysis of database from January 2006 to December 2011. One hundred and twenty eight women in 135 cycles on day five embryo transfer were included (1020 zygotes from 135 oocyte retrievals were followed from day one to five and morphological criteria were evaluated). To assess differences between groups, Student's t test and chi-squared test were used, and Odds ratio with CI 95\% determined signifi-
\end{abstract} cant associations.

Results: Overall results of 135 cycles with transfer on day five showed $47.4 \%$ clinical pregnancy rate (CPR) per cycle, $31.0 \%$ implantation rate (IR), 37.5\% multiple pregnancy rate (MPR) and $7.5 \%$ miscarriage rates (MR). 74 cycles in which $>2$ embryos reached the blastocyst stage allowed selection for transfer and also cryopreservation with $60.8 \% \mathrm{CPR}, 42.3 \% \mathrm{IR}, 40.0 \% \mathrm{MPR}$ and $6.6 \%$ MR (compared with the total population, statistical difference was observed only in the IR $(p=0.0456)$. On 30 cycles that patients were transferred with only expanded blastocyst on day 5 showed $76.7 \%$ CPR, $56.7 \%$ IR $43.5 \%$ MPR and $4.34 \%$ MR while 70 cycles of non-expanded blastocyst transfers showed $35.7 \%$ CPR, 24.2\% IR $44.0 \%$ MPR and $12.0 \%$ MR. Statistical difference was observed in the CPR $(p<0.0001)$ and IR $(p<0.0001)$ comparing expanded and not expanded transfers.

Conclusion: In selected cases, single blastocyst transfer can be performed with high implantation and clinical pregnancy rates. Four good quality embryos on day 3 will benefit from transfer at the blastocyst stage.

Key words: blastocyst, expanded blastocyst, single embryo transfer, multiple pregnancy rate

Objetivo: estabelecer critérios morfológicos para a seleção de blastocisto para decidir transferência embrionária única.

Métodos: Análise retrospectiva de dados de janeiro de 2006 a dezembro de 2011. Incluidas 128 mulheres em 135 ciclos, com transferência de embriões no dia 5 (1020 zigotos de 135 aspirações oocitárias avaliados morfologicamente a partir do dia 1). Para avaliar as diferenças entre os grupos, testes $t$ de Student e qui-quadrado foram usados, e odds ratio com IC $95 \%$ determinou associações significativas. Resultados: 135 ciclos com transferência no dia 5 apresentaram taxa de gravidez por ciclo de 47,4\% (CPR), taxa de implantação de $31,0 \%$ (IR), taxa de gravidez múltipla $37,5 \%$ (MPR) e $7,5 \%$ de aborto (MR). 74 ciclos em que $>2$ embriões atingiram o estágio de blastocisto permitiram a seleção para a transferência e também a criopreservação com 60,8\% CPR, IR de 42,3\%, MPR 40,0\% e 6,6\% MR (em comparação com a população total, houve dife- rença estatística apenas no IR ( $p=0,0456)$. Em 30 ciclos pacientes transferidas com blastocisto único expandido no dia 5 , houve $76,7 \%$ CPR, $56,7 \%$ de IR MPR, $43,5 \%$ e $4,34 \% \mathrm{MR}$, enquanto 70 ciclos de transferências de blastocistos não-expandidos mostrou CPR 35,7\%, 24,2\% de IR, MPR 44,0\% e 12,0\% MR (diferença estatística foi observada no CPR ( $p<0,0001)$ e IR ( $p<0,0001)$. Conclusão: Em casos seleccionados, a transferência de blastocisto único pode ser realizada, com taxa de implantação e de gravidez clínica altas. Quatro embriões de boa qualidade no dia 3 irão beneficiar a transferência no estágio de blastocisto

Palavras-chave: blastocisto; blastocisto expandido; transferência única; multigemelaridade.

\section{INTRODUCTION}

The development of appropriate culture conditions in the last decade has allowed embryos to be cultured in vitro for 5 days post oocyte retrieval and has been established as an effective selection tool of embryos for Assisted Reproductive Techniques (ART) (Thum et al. 2010).It has been demonstrated that the probability of live birth is significantly higher after blastocyst stage embryo transfer as compared to cleavage stage embryo transfer, when equal number of embryos are transferred (Papanikolaou et al., 2008; Glujovsky et al., 2012). Furthermore, in patients under 36 years old, single blastocyst transfer (SBT) can be performed, with higher pregnancy and delivery rates than cleavage stage embryo transfer with a significant drop in the rate of multiple births (Papanikolaou et al., 2006). Although, there appears to be a strong relationship between blastocyst quality and implantation (Balaban et al., 2000; Urman et al., 2007), very few studies report blastocysts characteristics the day of embryo transfer and its correlation with implantation and pregnancy rates (Gardner et al., 2000). Certainly, this is in contrast to the accurate description of cleavage-stage embryo morphology, when embryos are transferred on day 2 or 3, and its correlation with ART results since the beginning of ART (Lessey, 1998). Similar to methodology used in the cleavage-stage embryo, current blastocyst grading systems are mainly based upon morphological characteristics. The main objective of this study is to establish morphologic criteria for blastocyst selection to decide when to perform SBT.

\section{METHODS}

This is a retrospective analysis of embryology database collected from January 2006 to December 2011 at the Unit of Reproductive Medicine of the Department of 
Obstetrics and Gynecology at Clinica Las Condes, Chile. All patients signed institutional review board approved consent forms before initiating treatment and any patient specific identifiers were removed from database prior the analysis. One hundred and twenty eight women underwent 135 cycles in which embryo transfer was performed on day five. The mean age of women was $35.1 \pm 3.4$ years old and their mean basal FSH was 6.97 $\pm 2.59 \mathrm{mIU} / \mathrm{mL}$.

Intracytoplasmic sperm injection (ICSI) was performed in all cases. The oocytes were stripped of their cumulus cells after incubation in Hyaluronidase solution (80 UI/ $\mathrm{mL}$, Life Global ${ }^{\mathrm{TM}}$, USA) for 60 seconds. Spermatozoa were selected by swim up procedure and ICSI was performed with micropipettes (Humagen ${ }^{\mathrm{TM}}$, USA) under an Olympus inverted microscope and a Narishige micromanipulation system. Injected oocytes were incubated in Global Fertilization Media (Life Global ${ }^{\mathrm{TM}}$, USA) in a $6 \%$ CO2 incubator (Forma Scientific ${ }^{\text {TM }}$, USA)'. Eighteen hours after sperm injection oocytes were inspected for fertilization and those fertilized were transferred to Fresh Global Media (Life Global ${ }^{\mathrm{TM}}$, USA). A total of 1020 zygotes from 135 oocyte retrievals were followed from day one to five. Twenty four to 26 hours after ICSI, all zygotes were evaluated microscopically to assess whether the two pronucleous had disappeared or early cleavage had taken place. Number of cells and embryo morphology was assessed at day three using criteria reported by Veeck (Veeck, 1999), which considers cell number, uniformity and size of blastomeres, and the extent of fragmentation. Each embryo was designated based on its cell number and grade of uniformity and fragmentation, being grade 1 symmetric blastomeres without fragmentation, grade 2 a symmetric blastomeres and less than $20 \%$ of fragmentation, grade 2 b symmetric blastomeres and 20 to $50 \%$ of fragmentation, grade 3 uneven size of blastomeres, without fragmentation and grade 4 uneven blastomeres with fragmentation. Blastocyst formation an quality were evaluated on day five, using criteria reported by Veeck and Zaninovic (Veeck and Zaninovic 2003), where a good quality blastocyst is characterized by an early cavitation, resulting in the formation of an eccentric and expanded cavity lined by a distinct inner-cell mass and trophectoderm layer with a thin zona pellucida. Embryo transfer was performed with an ultrasound guided Frydman ultrasoft catheter ( $C C D^{\mathrm{TM}}$, France). Fourteen days after oocyte retrieval the patients were tested for pregnancy (Chorionic Gonadotropin $\beta$ subunit) and, if pregnant, an ultrasound was scheduled one and two weeks later to confirm a clinical pregnancy, register the number of gestational sacs and the presence of embryos with fetal heartbeats. Pregnancies were followed until 24 weeks of amenorrhea, to register those ending in miscarriages, and then until the delivery in all the cases. For statistical analysis the independent variable was blastocyst quality (expanded or not expanded) and primary outcomes were clinical pregnancy rate (transvaginal ultrasound confirmation of a gestational sac inside the uterine cavity), implantation rate (number of gestational sacs observed divided by the number of embryos transferred), multiple pregnancy rate and miscarriage rate (number of spontaneous clinical pregnancy losses divided by the number of clinical pregnancies). Continuous variables were described through means and standard deviation (normal distribution), categorical variables by proportions and rates and to assess differences between the two groups Student's t test and chi-squared test were used, respectively.

\section{RESULTS}

Results of the 135 cycles with embryo transfer on day five showed $47.4 \%(64 / 135)$ clinical pregnancy rate per cycle, $31.0 \%(89 / 287)$ implantation rate, $37.5 \%(24 / 64)$ multiple pregnancy rate and $7.5 \%(3 / 64)$ miscarriage rate. The mean of embryos transferred in these cycles was
$2.13 \pm 0.48$. Results in a group of 74 cycles, in which more than two embryos reached the blastocyst stage and this allowed blastocyst selection for transfer and also cryopreservation of the remaining showed $60.8 \%$ (45/74) clinical pregnancy rate per cycle, $42.3 \%$ (63/149) implantation rate, $40.0 \%(18 / 45)$ multiple pregnancy rate and $6.6 \%$ (3/45) miscarriage rates. The mean of embryos transferred in this group was $2.01 \pm 0.35$ (Figure 1 ). If compared with the total population (TP), statistical difference was observed only in the implantation rate $(p=0.0456 ; \mathrm{CI}$ 0.90 to 21.70 ). On the other hand, pregnancy rate, multiple pregnancy rate and mean embryo transferred were not significantly different.

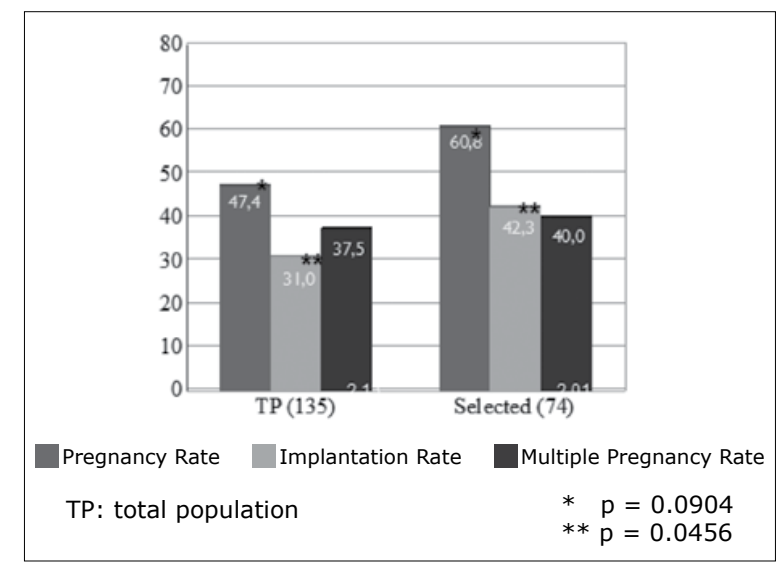

Figure 1. Pregnancy, implantation and multiple pregnancy rates for day 5 embryo transfer

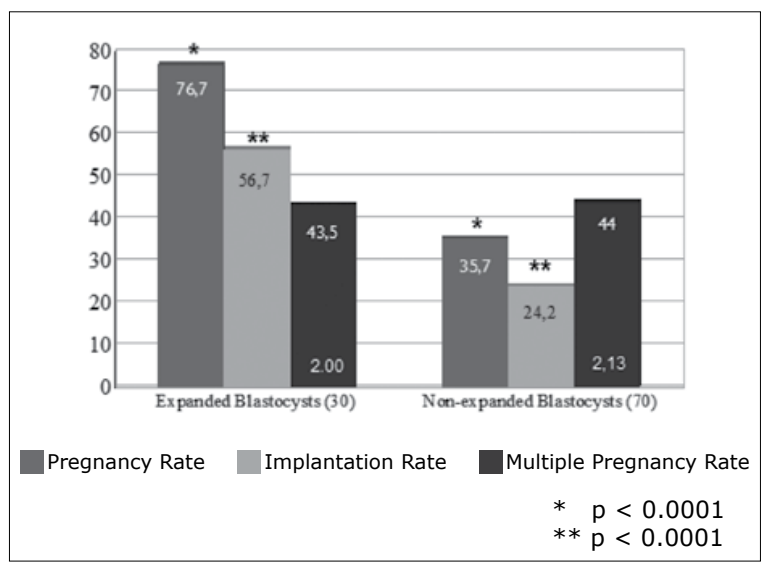

Figure 2. Pregnancy, implantation and multiple pregnancy rates for transfers of expanded and not expanded blastocysts

Results on 30 cycles with another selection criteria, in which patients were transferred with only expanded blastocysts on day 5 , showed $76.7 \%(23 / 30)$ clinical pregnancy rate per cycle, $56.7 \%$ (34/60) implantation rate, $43.5 \%(10 / 23)$ multiple pregnancy rate and $4.34 \%(1 / 23)$ miscarriage rates. The mean of embryos transferred was $2.00 \pm 0.00$. Seventy cycles of non-expanded blastocyst transfers showed $35.7 \%(25 / 70)$ clinical pregnancy rate per cycle, $24.2 \%$ (36/149) implantation rate, 44.0\% (11/25) multiple pregnancy rate and $12.0 \%$ (3/25) miscarriage rates. The mean of embryos transferred was $2.14 \pm 0.54$ (Figure 2). Statistical difference was observed in clinical pregnancy rate ( $p<0.0001 ;$ CI 22.16 to 59.84 ) and implantation rate ( $p<$ $0.0001 \mathrm{CI} 17.99$ to 46.81 ), if the group of expanded and not expanded blastocysts transferred were compared. Multiple pregnancy rates and the mean of embryos transferred did not have significant differences in both groups. 
Table 1. Clinical characteristics of patients with at least one expanded blastocyst transferred (* Grade 1 and $2 a$ ).

\begin{tabular}{lc}
\hline Age & $34,8 \pm 3,4$ \\
\hline Basal FSH & $6,4 \pm 1,2$ \\
\hline Follicles & $17,8 \pm 7,1$ \\
\hline Oocytes retrieved & $13,7 \pm 5,8$ \\
\hline Zygotes & $7,9 \pm 2,9$ \\
\hline $\begin{array}{l}\text { Day 3 Good } \\
\text { quality embryos* }\end{array}$ & $4,4 \pm 1,9$ \\
\hline
\end{tabular}

Table 1 shows clinical characteristic of women having at least one expanded blastocyst. This group of patients had a mean age of $34.8 \pm 3.4$ years old, $6.4 \pm 1.2 \mathrm{U} / \mathrm{L}$ of basal $\mathrm{FSH}, 17.8 \pm 7.1$ mean number of $>18 \mathrm{~mm}$ follicles, $13.7 \pm 5.8$ mean number of oocytes retrieved, $7.9 \pm 2.9$ mean number of zygotes and $4.4 \pm 1.9$ mean number of good quality embryos analyzed at day three of development.

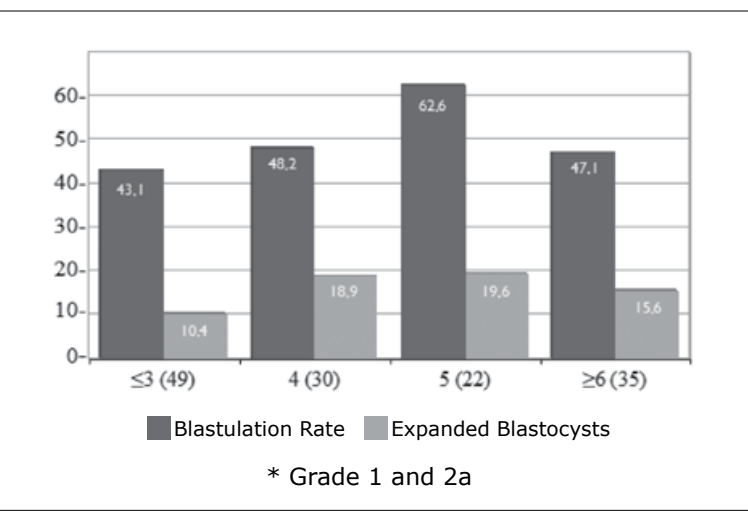

Figure 3. Blastulation rate and proportion of expanded blastocysts in patients transferred on day 5 , according to the number of good quality embryos on day $3^{*}$

Regarding the number of good quality embryos on day 3 of development and the probability of blastocyst formation and expanded blastocyst rate were $43.1 \%$ and $10.4 \%$ in 49 cycles with $\leq 3$ good quality embryos, $48.2 \%$ and $18.9 \%$ in 30 cycles with 4 good quality embryos, $62.6 \%$ and $19.6 \%$ in 22 cycles with 5 good quality embryos and $47.1 \%$ and $15.6 \%$ in 35 cycles with $\geq 6$ good quality embryos, respectively (Figure 3 ).

\section{DISCUSSION}

As is shown in figure 1 , when blastocyst selection could be applied, because enough number of day five embryos are available, there is a trend to increase pregnancy rates and statisticaly significant higher implantation rates. This first selection step provides an implantation rate of $42.3 \%$, suggesting that SBT could be offered to this group of patients with acceptable pregnancy rate and very low multiple pregnancy rate.

On the other hand, as has been suggested by Balaban et al. (Balaban et al., 2006), an accurate blastocyst grading system provides a good selection of blastocysts with the highest implantation potential. Blatoscyst expansion, described by Veeck and Zaninovic (Veeck and Zaninovic 2003), is the next step in day five embryo selection used in this study. A statisticaly significant increase in pregnany rate an implantation rate was observed in patients who received expanded if compared with those who received not expanded blastocysts. Implantation rate for this group of patients suggest that SBT should be offered when at least one blastocyst with an early cavitation, resulting in the formation of an eccentric and expanded cavity lined by a distinct inner-cell mass and trophectoderm layer with a thin zona pellucida is observed on day 5 . This group of patients has pregnancy rates as high as $55 \%$ to $60 \%$, as was also reported by Gardner et al (Gardner et al., 2000). This results demostrate that SBT is an effective method in this selected group of patients (Gardner et al.. 2004).

Although, results reported in this study demonstrate the value of SBT, the group of patients in which this is possible is reduced. Table 1 shows clinical characteristics of patients having at least one expanded blastocysts for embryo transfer on day 5 . This selected group of women are young, with normal ovarian reserve, with high number of follicles and retrieved oocytes, with a mean of $7.9 \pm 2.9$ zygotes and $4.4 \pm 1.9$ grade 1 and $2 a$ embryos on day 3 , which is in agreement with clinicals characteristics previously reported by other authors (Rijnders and Jansen, 1998; Mangalraj et al., 2009; Thomas et al.. 2010).

On the other hand, figure 3 shows that is more likely to have at least one expanded blastocyst to transfer when $\geq 4$ good quality embryos (grade 1 and $2 a$ ) are available on day 3 , which is the number also suggested by others (Papanikolaou et al., 2005; Dessolle et al., 2010) as the minimum required for extended embryo culture until day 5 . However, Balaban et al suggested that blastocyst transfer is possible even in patients not having good quality embryos on day 3 with better results than if the same fair or poor quality embryos were actually transferred on day 3 (Balaban et al., 2001).

Conclusion: In selected cases, single blastocyst transfer can be performed with high implantation and clinical pregnancy rates and this could lead to a reduction of higher-order pregnancies and multiple births. Four good quality embryos on the day 3 of embryo development indicates that the patient will benefit from embryo transfer at the blastocyst stage and have a better chance of achieving a clinical pregnacy and finally delivery than with cleavage-stage embryo transfer.

\section{Corresponding author}

Dr. Javier Crosby, Ph.D.

Unit of Reproductive Medicine, Department of Obstetrics and Gynecology, Clinica Las Condes, Lo Fontecilla 441, Santiago, Chile, Postal Code 7591046.

Telephone: 560222104000

Mail: jcrosby@clc.cl

\section{REFERENCES}

Balaban B, Urman B, Alatas C, Mercan R, Aksoy S, Isiklar A. Blastocyst-stage transfer of poor-quality cleavage-stage embryos results in higher implantation rates. Fertil Steril. 2001; 75(3):514-518.

Balaban B, Yakin K, Urman B. Randomized comparison of two different blastocyst grading systems. Fertil Steril. 2006; 85(3):559-563.

Dessolle L, Freour T, Barriere P, Darai E, Ravel C, Jean M, Coutant C. A cycle-based model to predict blastocyst transfer cancellation. Hum Reprod. 2010; 25:598-604.

Gardner DK, Lane M, Stevens J, Schlenker T, Schoolcraft WB. Blastocyst score affects implantation and pregnancy outcome: towards a single blastocyst transfer. Fertil Steril. 2000; 73(6): 1155-1158.

Gardner DK, Surrey E, Minjarez D, Leitz A, Stevens J, Schoolcraft WB. Single blastocyst transfer: a prospective randomized trial. 2004; Fertil Steril 81(3):551-555.

Glujovsky D, Blake D, Farquhar C, Bardach A. Cleavage stage versus blastocyst stage embryo transfer in assisted reproductive technology. Cochrane Database Syst Rev. 2012; 7: CD002118.

Lessey BA. Embryo quality and endometrial receptivity: lessons learned from the ART experience. 1998; J Assist Reprod Genet 15(4):173-176.

Mangalraj AM, Muthukumar K, Aleyamma TK, Kamath MS, George K. Blastocyst stage transfer vs cleavage stage embryo transfer. 2009; J Hum Reprod Sci 2(1): 23-26. 
Papanikolaou EG, D'Haeseleer E, Verheyen G, Van de Velde $H$, Camus M, Van Steirteghem A, Devroey P, Tournaye H. Live birth rate is significantly higher after blastocyst transfer than after cleavage-stage embryo transfer when at least four embryos are available on day 3 of embryo culture. A randomized prospective study. Hum Reprod. 2005; 20:3198-3203.

Papanikolaou EG, Kolibianakis EM, Tournaye $H$, Venetis CA, Fatemi H, Tarlatzis B, Devroey P. Live birth rates after transfer of equal number of blastocysts or cleavage-stage embryos in IVF. A systematic review and meta-analysis. Hum Reprod. 2008; 23:91-99.

Papanikolaou EG, Camus M, Kolibianakis EM, Van Landuyt L, Van Steirteghem A, Devroey P. In vitro fertilization with single blastocyst-stage versus single cleavage-stage embryos. 2006; N Engl J Med 354(11):1139-1146.

Rijnders PM \& Jansen CA. The predictive value of day 3 embryo morphology regarding blastocyst formation, pregnancy and implantation rate after day 5 transfer following in-vitro fertilization or intracytoplasmic sperm injection. Hum Reprod. 1998; 13:2869-2873.

Thomas MR, Sparks AE, Ryan GL, Van Voorhiset BJ. Clinical predictors of human blastocyst formation and pregnancy after extended embryo culture and transfer. 2010; Fertil Steril 94(2):543-548.

Thum MY, Wells V, Abdalla H. Patient selection criteria for blastocyst culture in IVF/ICSI treatment. 2010; J Assist Reprod Genet 27(910):555-560.

Urman B, Yakin K, Ata B, Balaban B. How can we improve current blastocyst grading systems? 2007; Curr Opin Obstet Gynecol 19(3): 273-278.

Veeck LL. An atlas of human gametes and conceptuses : an illustrated reference for assisted reproductive technology. New York: London, Parthenon; 1999.

Veeck LL \& Zaninovic N. An atlas of human blastocysts. Boca Raton: London, Parthenon; 2003. 